MIGUEL ÁNGEL BARRETO

\title{
EL CRECIMIENTO URBANO DE LAS CIUDADES INTERMEDIAS DEL N.E. ARGENTINO EN EL CONTEXTO DE LAS TRANSFORMACIONES REGIONALES[1]
}

El autor es arquitecto (UNNE, Argentina), magíster en antropología social (UNaM, Argentina), docente e investigador de la FAU, UNNE, Argentina.

\begin{abstract}
RESUMEN. EI presente trabajo analiza las principales características del crecimiento urbano de las ciudades intermedias (capitales provinciales) de la región nordeste de la Argentina, durante la década del noventa, en el marco de las transformaciones estructurales ocurridas durante este periodo, Al respecto, analiza las características sobresalientes del proceso de urbanización regional, la distribución de la población en el territorio y el rol protagónico desempeñando por las ciudades capitales de provincia en la actual reestructuración territorial de la población. El trabajo también aborda el análisis de los aspectos más importante del crecimiento urbano de estas ciudades durante este periodo y los resultados en el espacio urbano que los mismos trajeron aparejados y que han contribuido a definir un espacio urbano de mayor contraste y fragmentación social.
\end{abstract}

ABSTRACT. THE URBAN GROWTH IN MEDIUM-SIZED CITIES IN THE NORTH-EAST OF ARGENTINA, IN A CONTEXT OF REGIONAL TRANSFORMATION.

This article analysis the main features of structural transformation of urban growth occurred during the 1990's in the provincial capital cities located in the Northeast of Argentina. It examines the relevance of regional urbanization process the influences of population distribution and the role of medium-sized cities within territorial re-structuration. This article then examines in detail other aspects of urban growth and its spatial dimensions, which contributes in the formation of urban spaces characterized by important contrast and social fragmentation.

\section{EL NORDESTE ARGENTINO Y LAS TRANSFORMACIONES ESTRUCTURALES[2]}

La región Nordeste de la Argentina ha experimentado durante la ultima década del siglo pasado importantes cambios, en parte, asociados, a las transformaciones estructurales que han ocurrido en el país durante la década del noventa, tales como la reforma del Estado, la privatización de las empresas públicas, la apertura económica y la concentración y centralización del capital (Basualdo, 2001) y, en parte, asociados al impacto de la globalización económica en América Latina, expresada en la región por la integración de los principales mercados del Sur (MERCOSUR). Estos cambios tienen múltiples expresiones, en el campo de la economía, por ejemplo, se produjo un importante estancamiento en la evolución del PGB, como consecuencia del deterioro sufrido por la actividad primaria -principal sector de la economía regional, en particular las actividades agrícolas y ganaderas- que, a la luz de la concentración económica producida, afectó especialmente a las unidades productoras de escalas pequeñas y medianas, mientas que, en contraste a esta situación, se produjo una fuerte modernización tecnológica en el sector de servicios y se realizaron considerables obras de infraestructuras con financiación pública, merced a importantes flujos de créditos de organismos financieros internacionales, realizadas en el marco de la reestructuración territorial propiciada por las reformas en marcha, cuyos efectos sobresalientes, tal como señala Laurelli (en esta misma publicación), son de fragmentación, centralización, concentración, segregación, etcétera y que en el campo social, situaron al NEA como la región más afectada de la Argentina, con alarmantes valores en los indicadores de pobreza, salud, educación, seguridad social y el empleo (Siempro, 2000) e importantes efectos sobre el asentamiento territorial de la población. En este contexto, uno de los fenómenos importantes de la región es la consolidación del acelerado proceso de urbanización de los centros urbanos que son capitales provinciales (Resistencia, Corrientes, Formosa y Posadas). El 
presente artículo, precisamente, analiza algunas de las características sobresalientes de este proceso en el marco de las transformaciones estructurales aludidas.

\section{EL PROCESO DE URBANIZACIÓN REGIONAL}

Si bien la región Nordeste, según los resultados del Censo de Población y Vivienda 2001 (INDEC, 2001), presenta aún un porcentaje elevado de población rural (24\%) con respecto al total del país $(10,40 \%)$, la misma se encuentra atravesando en las últimas décadas un proceso de urbanización más acelerado que el del total del país, el incremento porcentual de población urbana desde 1980 hasta el año 2000 fue en el total del país de 8,3 puntos mientras que en la región NEA fue de 26,2 puntos. Aunque, sin embargo, debe señalarse también, que la misma presenta diferencias importantes entre sus provincias, siendo la provincia de Corrientes la que menor cantidad de población rural tiene actualmente $(19,70 \%)$ y Misiones la mayor de ellas $(27,10 \%)$.[3]

Gráfico 1. Crecimiento porcentual de la población urbana de la Región NEA y el Total de País, 1980/00. Elab. propia en base al INDEC, Serie Análisis Demográfico No 7.

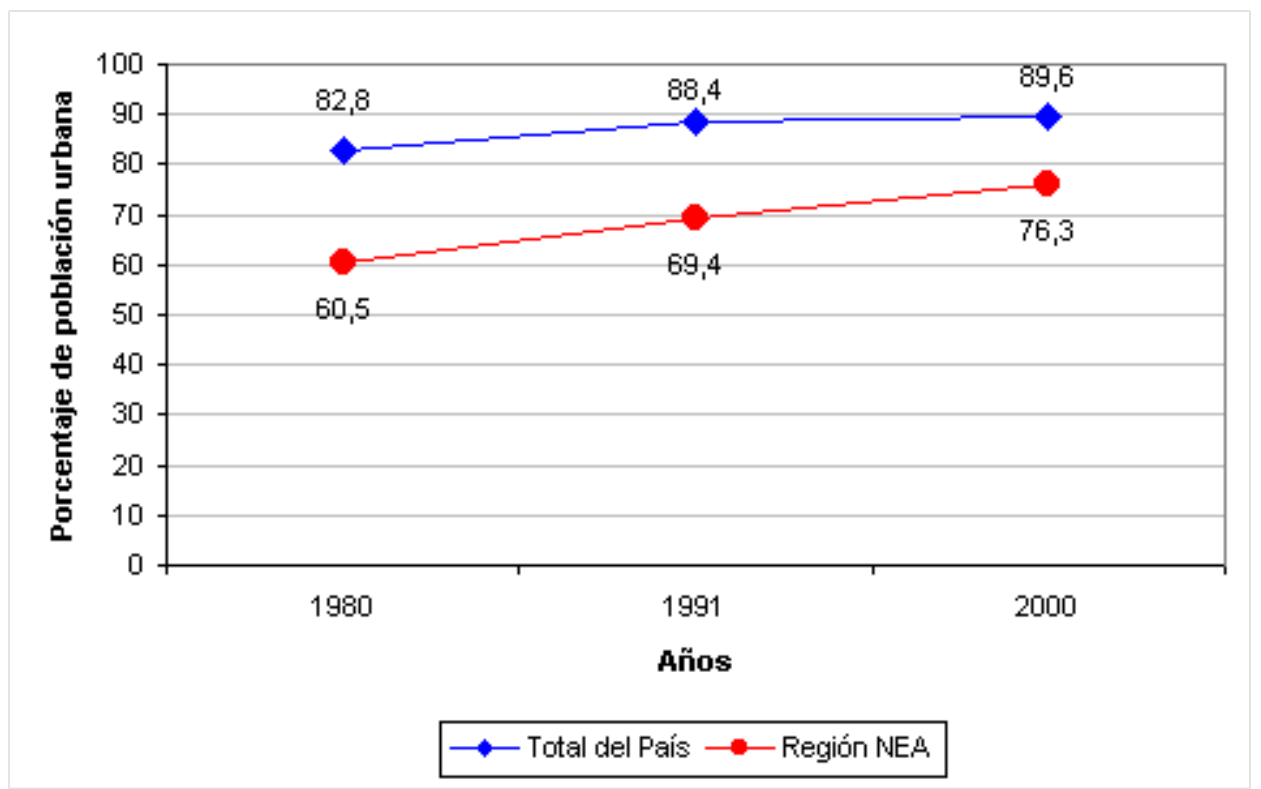

Gráfico 2. Porcentaje de Población Rural de la Región NEA y el Total de País, Mayo 2000. Elaboración propia en base al INDEC, Serie Análisis Demográfico No 7. 


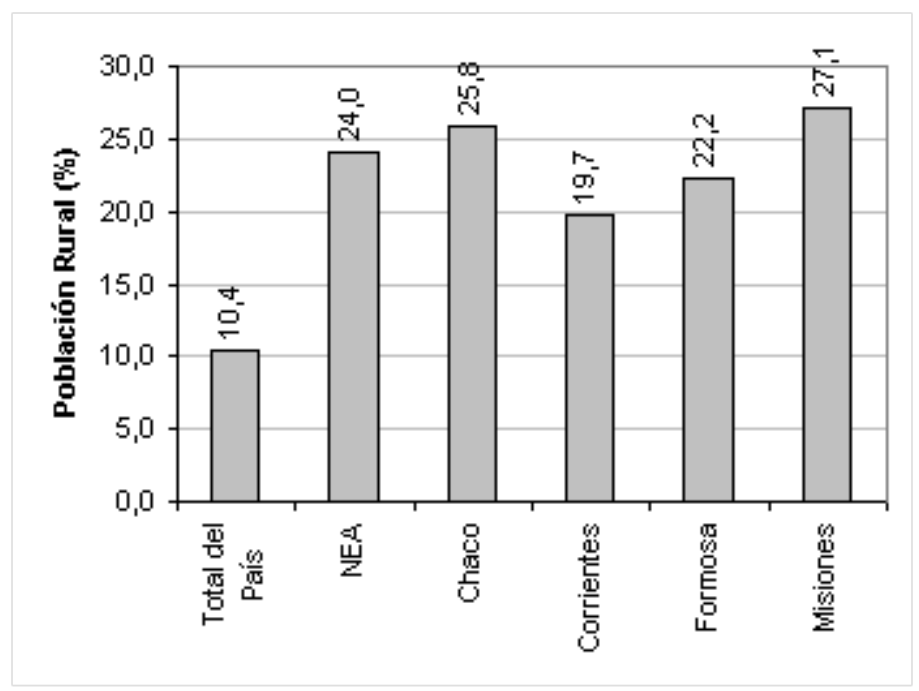

Por otra parte, este proceso de urbanización tiene como principal protagonista a las ciudades capitales de cada una de estas provincias. Tal como ya se ha señalado en un trabajo anterior (Barreto I Sánchez, 2000), la población de todos los departamentos capitales de las provincias de la región NEA (en los que se encuentran los centros urbanos de Gran Resistencia, Corrientes, Posadas y Formosa) creció en las últimas décadas a un ritmo mucho mayor que el de las provincias a las que pertenecen.

Gráfico 3. Crecimiento porcentual de la población provincial y de los departamento capitales de la Región NEA, 2001/91. Elab. propia en base a los Censos 1991/2001 (INDEC).

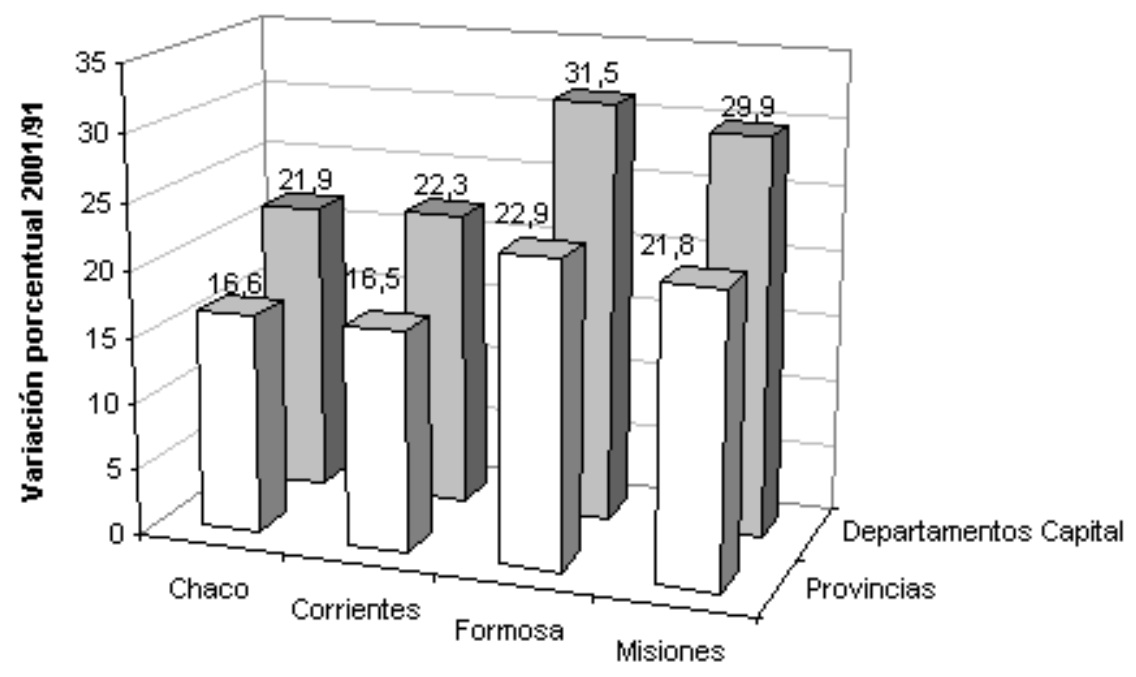

Esta característica también se repite con relación a los grandes conglomerados urbanos, como el caso de la Capital Federal y el Gran Buenos. Este es uno de los aspectos más importantes para destacar del proceso de crecimiento poblacional de las ciudades capitales del NEA argentino en las últimas décadas del siglo XX, ya que el mismo se inscribe dentro de lo que autores como Lungo (1995: 81110), han destacado como una característica del nuevo patrón de urbanización de América Latina, el cual, está dada por el mayor crecimiento relativo de las ciudades intermedias o secundarias, con relación a las grandes ciudades del continente, en contraposición al periodo comprendido entre mediados de siglo XX y la década del setenta, en que fueron las grandes ciudades de más de un millón de habitantes -generalmente capitales nacionales- las que lo hicieron.[4] 
El mayor crecimiento poblacional de estas ciudades, respecto a la población total de las provincias a las que pertenecen, se debió tanto a la migración rural, como a la que se dio, desde los poblados de menor tamaño que se encuentran dentro de sus áreas de influencia. La mayoría de los departamentos con centros urbanos de entre 50 y 100 mil habitantes de estas provincias tuvieron en las últimas décadas un crecimiento porcentual de población menor que el de los departamentos capitales de sus respectivas provincias, en el caso del Chaco, el único centro urbano inscripto dentro de esta categoría es, actualmente, Roque S. Peña, ubicado en el departamento Comandante Fernández, que según los resultados provisorios del censo 2001, tuvo un crecimiento de población con relación al censo de 1991 del 12,9\%, mientras que el Departamento San Fernando, donde se encuentra el Gran Resistencia, tuvo un crecimiento del $21,9 \%$ durante el mismo periodo.

\begin{tabular}{|l|l|l|l|}
\hline CHACO & Censo & $\begin{array}{l}\text { Censo } \\
2001\end{array}$ & $\begin{array}{l}\text { Crecimiento } \\
\text { Porcentual }\end{array}$ \\
\cline { 1 - 4 } Departamentos & 1991 & 62.321 & 42,4 \\
\hline Gral. Güemes & 43.762 & 29.058 & 40,8 \\
\hline Almirante Brown & 20.645 & 9.171 & 31,5 \\
\hline 1 de Mayo & 6.975 & 10.741 & 22,1 \\
\hline Libertad & 8.800 & 364.002 & 21,9 \\
\hline San Fernando & 298.572 & 27.192 & 18,1 \\
\hline Chacabuco & 23.015 & 13.440 & 17,3 \\
\hline Gral. Donovan & 11.456 & 15.010 & 17,0 \\
\hline Sargento Cabral & 12.828 & 978.956 & 16,6 \\
\hline Total Provincial & 839.677 & 27.890 & 15,1 \\
\hline 25 de Mayo & 24.223 & 87.654 & 12,9 \\
\hline C. Fernández & 77.619 & 20.764 & 12,8 \\
\hline Independencia & 18.403 & 12.149 & 12,2 \\
\hline Pcia. De la Plaza & 10.828 & 4.043 & 12,1 \\
\hline Tapenagá & 3.605 & 53.229 & 11,1 \\
\hline Gral. San Martín & 47.917 & 27.054 & 9,7 \\
\hline 9 de Julio & 24.654 & 53.617 & 9,6 \\
\hline M. J. L. Fontana & 48.904 & 14.336 & 7,0 \\
\hline San Lorenzo & 13.394 & 31.714 & 6,1 \\
\hline Quitilipi & 29.895 & 10.499 & 4,7 \\
\hline Gral. Belgrano & 10.031 & 23.680 & 2,8 \\
\hline Bermejo & 23.046 & 24.740 & $-0,8$ \\
\hline Maipú & 24.933 & 19.203 & $-7,1$ \\
\hline O'Higgins & 20.661 & 20.117 & $-8,2$ \\
\hline 12 de Octubre & 21.909 & 9.907 & $-27,2$ \\
\hline F. J. S. M. De Oro & 13.603 & & \\
\hline
\end{tabular}

En la provincia de Formosa, por su parte, actualmente no existen centros urbanos de entre 50 y 100 mil habitantes, y el Departamento Pilcomayo, en el que se encuentra la ciudad fronteriza de Clorinda, que es el centro urbano que le sigue en tamaño a la ciudad de Formosa, ha crecido entre los censos de 1991 y 2001 tan sólo un 16,5\%, mientras que el Departamento Formosa, lo a hecho en un 31,1\%.

\begin{tabular}{|l|l|l|l|}
\hline FORMOSA & $\begin{array}{l}\text { Censo } \\
1991\end{array}$ & $\begin{array}{l}\text { Censo } \\
2001\end{array}$ & $\begin{array}{l}\text { Crecimiento } \\
\text { Porcentual }\end{array}$ \\
\cline { 1 - 4 } Departamentos & 6.650 & 10.917 & 64,2 \\
\hline Ramón Lista & 8.355 & 12.107 & 44,9 \\
\hline Matacos & 159.545 & 209.804 & 31,3 \\
\hline Formosa & 10.143 & 12.616 & 24,4 \\
\hline Bermejo & 398.413 & 489.751 & 22,9 \\
\hline Total Provincia & 13.581 & 16.289 & 19,9 \\
\hline Laishi & 57.277 & 68.330 & 19,3 \\
\hline Pirané & 67.012 & 78.074 & 16,5 \\
\hline Pilcomayo & 58.472 & 64.197 & 9,8 \\
\hline Patiño & 17.378 & 17.417 & 0,2 \\
\hline Pilagás & & & \\
\hline
\end{tabular}


En la provincia de Misiones, en cambio, existen tres centros urbanos que tienen actualmente entre 50.000 y 100.000 habitantes, estos son Eldorado, Oberá y Puerto Iguazú, sin embargo, los departamentos de igual nombre que los contienen, entre los censos de 1991 y 2001, han tenido un crecimiento de población del 20,3\%, 14,6\% y 14,4\% respectivamente, valores todos ellos, inferiores al 29,9\% del departamento Capital.

\begin{tabular}{|c|c|c|c|}
\hline MISIONES & \multirow{2}{*}{$\begin{array}{l}\text { Censo } \\
1991 \\
\end{array}$} & \multirow{2}{*}{$\begin{array}{l}\text { Censo } \\
2001 \\
\end{array}$} & \multirow{2}{*}{$\begin{array}{l}\text { Crecimiento } \\
\text { Porcentual }\end{array}$} \\
\hline Departamentos & & & \\
\hline Candelaria & 15.121 & 22.227 & 47,0 \\
\hline G. M. Belgrano & 24.552 & 33.597 & 36,8 \\
\hline San Pedro & 18.031 & 23.744 & 31,7 \\
\hline Guaraní & 42.948 & 56.550 & 31,7 \\
\hline Capital & 218.685 & 284.123 & 29,9 \\
\hline Apóstoles & 28.925 & 37.494 & 29,6 \\
\hline Total Provincial & 788.915 & 961.274 & 21,8 \\
\hline Eldorado & 55.861 & 67.177 & 20,3 \\
\hline San Ignacio & 46.301 & 54.833 & 18,4 \\
\hline Leandro N. Alem & 35.182 & 41.591 & 18,2 \\
\hline Oberá & 83.399 & 95.562 & 14,6 \\
\hline Iguazú & 57.623 & 65.943 & 14,4 \\
\hline Montecarlo & 30.062 & 33.957 & 13,0 \\
\hline L. G. San Martín & 37.722 & 42.026 & 11,4 \\
\hline 25 de Mayo & 24.422 & 27.161 & 11,2 \\
\hline Concepción & 8.251 & 9.018 & 9,3 \\
\hline San Javier & 17.693 & 19.284 & 9,0 \\
\hline Cainguás & 44.137 & 46.987 & 6,5 \\
\hline
\end{tabular}

En la provincia de Corrientes, por su parte, existen un sólo centro urbano que tiene actualmente entre 50.000 y 100.000 habitantes, este es el de Goya, sin embargo, el departamento de igual nombre que los contiene, entre los censos de 1991 y 2001, solamente ha tenido un crecimiento de población del $9,6 \%$, valor éste, inferior al 18,2\% del departamento Capital.

\begin{tabular}{|l|l|l|l|}
\hline CORRIENTES & Censo & $\begin{array}{l}\text { Censo } \\
2001\end{array}$ & $\begin{array}{l}\text { Crecimiento } \\
\text { Porcentual }\end{array}$ \\
\cline { 1 - 3 } Departamentos & 1991 & 13.047 & 26,4 \\
\hline San Cosme & 9.598 & 26.185 & 25,7 \\
\hline Savalle & 19.457 & 53.807 & 19,4 \\
\hline Concepción & 43.360 & 18.407 & 19,3 \\
\hline Capital & 14.856 & 327.787 & 18,2 \\
\hline Itatí & 268.080 & 8.717 & 17,1 \\
\hline Total provincial & 7.228 & 926.989 & 16,5 \\
\hline Esquina & 26.159 & 30.240 & 13,5 \\
\hline Mercedes & 33.948 & 39.170 & 13,3 \\
\hline Monte Caseros & 29.390 & 33.652 & 12,7 \\
\hline S. L. del Palmar & 14.336 & 16.360 & 12,4 \\
\hline Bella Vista & 30.966 & 35.326 & 12,3 \\
\hline P. de los Libres & 41.129 & 46.122 & 10,8 \\
\hline San Roque & 16.039 & 17.934 & 10,6 \\
\hline Empedrado & 13.188 & 14.696 & 10,3 \\
\hline San Miguel & 9.169 & 10.216 & 10,2 \\
\hline San Martín & 11.017 & 12.202 & 9,7 \\
\hline Goya & 78.894 & 87.233 & 9,6 \\
\hline Mburucuyá & 8.188 & 8.998 & 9,0 \\
\hline Saladas & 19.747 & 21.437 & 7,9 \\
\hline General Alvear & 7.493 & 8.102 & 7,5 \\
\hline General Paz & 13.764 & 14.710 & 6,4 \\
\hline & & & \\
\hline
\end{tabular}




\begin{tabular}{|l|l|l|l|} 
Ituzaingó & 28.685 & 30.524 & 6,0 \\
\hline Curuzú Cuatiá & 39.922 & 42.043 & 5,0 \\
\hline Sauce & 8.703 & 9.079 & 4,1 \\
\hline Berón de Astrada & 2.280 & 2.296 & 0,7 \\
\hline
\end{tabular}

Este proceso que ha ocurrido en el NEA, a su vez, se encuentra en concordancia con lo ocurrido en todo el país. Aunque no se disponen aún de los datos de lo ocurrido en la década del noventa, durante el periodo 1980-91, en la Argentina, el número de ciudades de entre 100 mil y 1 millón de habitantes rango dentro del que se inscriben Resistencia, Corrientes, Formosa y Posadas- se incrementó un $36,8 \%$, en cambio, el número de ciudades entre 50 mil y 100 mil habitantes solamente se incrementó el 16,7\% (INDEC, Anuario Estadístico 2000). Esto reafirma el rol que actualmente está desempeñando esta categoría de ciudad, en la estructuración territorial de la población.

Sin embargo, el proceso migratorio interno de cada una de las provincias de la región NEA presentan sus particularidades. En Misiones los departamentos del nordeste (Gral. M. Belgrano, San Pedro y Guaraní), aunque contienen poca población, han creciendo porcentualmente más que el propio Departamento Capital, debido a la llamada "expansión de la frontera agrícola", algo similar, aunque en menor proporción, ocurre con los departamentos más urbanizados del norte (Puerto Iguazú y Eldorado), que señala que el conglomerado urbano fronterizo internacional de Puerto Iguazú (Argentina), Ciudad del Este (Paraguay) y Foz del Iguazú (Brasil) representan a su vez un polo importante de atracción de población dentro de la provincia. Otro departamento que también evidencia un crecimiento porcentual mayor que el departamento capital es Candelaria, pero en este caso se debe a su vecindad con el Departamento Capital, ya que se está transformando en un conglomerado satélite de la ciudad de Posadas, Situaciones similares a esta última ocurre con el Departamento San Cosme, en relación con el Departamento Capital de Corrientes y el Departamento Lavalle, en relación con el de Goya, también de la provincia de Corrientes y los Departamentos Primero de Mayo y Libertad, en relación con el de San Fernando, en la provincia del Chaco. La provincia de Misiones, a la vez, no presenta durante este periodo, ningún departamento cuya población esté decreciendo y presenta una distribución espacial más homogénea de su población con respecto a las otras provincias del NEA, ya que tiene, además de los tres centros urbanos de entre 50.000 y 100.000 habitantes ya citados, otros cinco, de entre 20.000 y 50.000 habitantes, diseminados por el territorio provincial (Montecarlo, Puerto Rico, Jardín de América Aristóbulo del Valle y Apóstoles).

En situación más parecida a la de Misiones se encuentra la provincia de Corrientes, dado que, a pesar de que presenta un solo centro urbano de entre 50.000 y 100.000 habitantes (Goya), presenta varios departamentos al nordeste y el sur de la provincia que han tenido un crecimiento de población igual o más acelerado que el propio Departamento Capital y que disponen de centros urbanos de entre 20.000 y 50.000 habitantes, tal como Santo Tomé, Virasoro, Ituzaingó, Paso de los Libres, Monte Caseros, Curuzú Cuatiá y Mercedes. En cambio, El Chaco, presenta entre el periodo 1991-2001, aparte de Roque Sáenz Peña, solamente dos centros urbanos de entre 20.000 y 50.000 habitantes (Gral. San Martín y Villa Ángela), cuatro departamentos que están decreciendo y el Departamento Capital supera ampliamente el crecimiento porcentual de todos los demás, a excepción de los departamentos Gral. Güemes y Alt. Brown, que tienen poca población y ningún centro urbano importante. Lo que evidencia, en cierta forma un desarrollo territorial provincial bastante desquilibrado, en el que la capital provincial y su área circundante aparecen como único polo importante de atracción de población en toda la provincia e importantes áreas rurales en proceso de despoblamiento. Situación algo parecida presenta la provincia de Formosa, en el que los departamentos que presentan un crecimiento igual o mayor al Capital, tienen muy poca población y ningún centro urbano importante (Ramón Lista, Matacos y Bermejo), aunque esta provincia no presenta ningún departamento cuya población esté decreciendo).

Mapa 1. Nordeste Argentino, crecimiento porcentual de población por departamento 2001/91 y Centros urbanos de más de 20.000 habitantes. Elaboración propia en base a los Censos 1991/2001 (INDEC). 


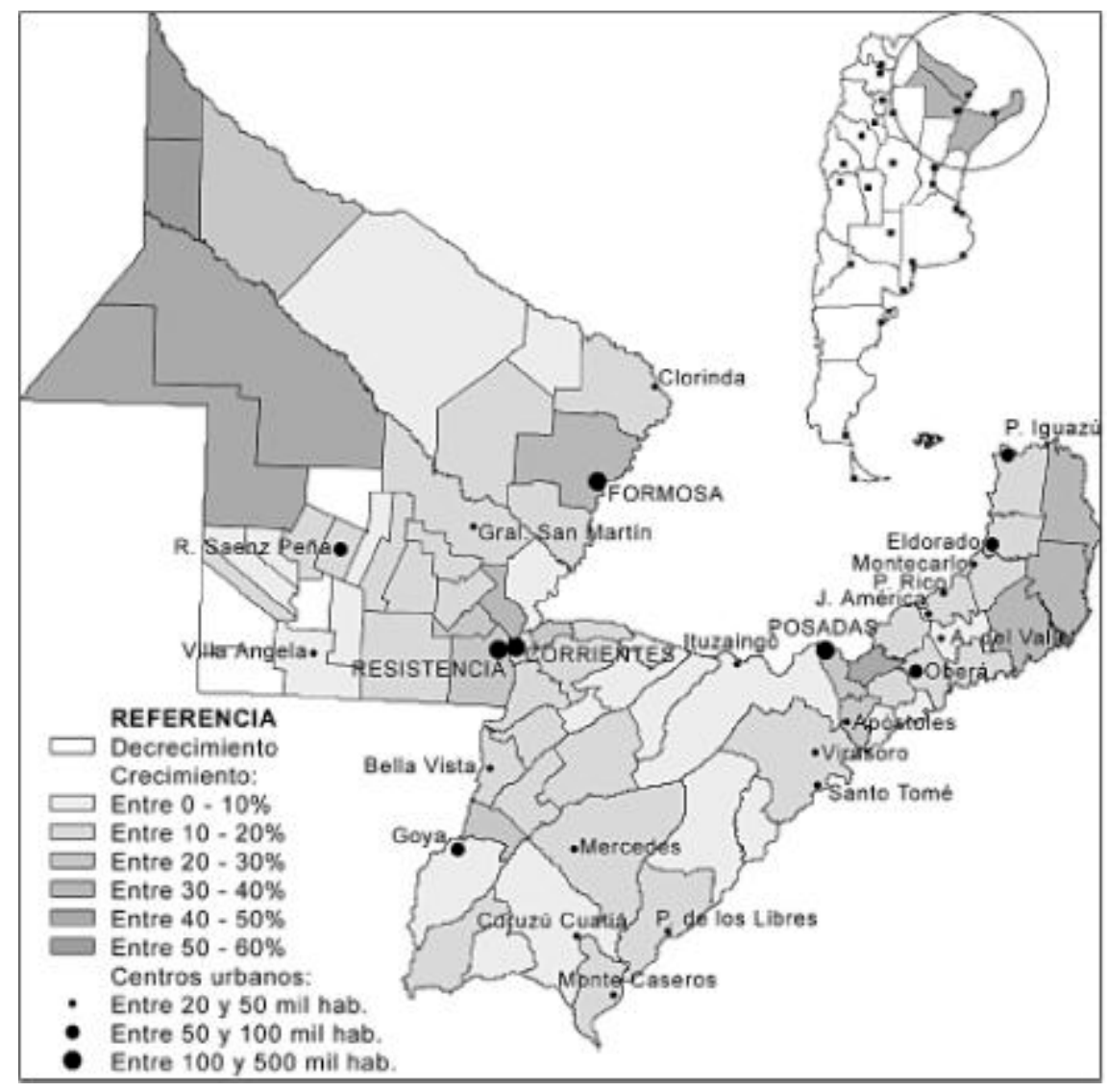

El ritmo de urbanización seguido por cada una de las provincias y sus departamentos capitales, también presentan particularidades plausibles de ser analizadas, tal como ya se señaló anteriormente, la provincia de Misiones es la que presenta el mayor porcentaje de población rural $(27,1)$, pero a la vez, durante el periodo 1991/2000, tuvo el ritmo más acelerado de crecimiento de la población urbana $(14,3 \%)$ y el segundo valor de crecimiento de la población de su Departamento Capital, lo que permite deducir que esta provincia presenta un importante proceso de migración de población hacia su ciudad Capital y su área inmediata de influencia. La que le sigue en un ritmo de urbanización similar es la provincia de Formosa, que si bien, la población de su Departamento Capital, se incremento un par de puntos más que el de la provincia de Misiones, presenta un menor porcentaje de población rural $(22,2 \%)$ y un menor incremento de su población urbana (13\%). Por su parte, las provincias de Corrientes y Chaco, presentan un menor incremento porcentual tanto de población urbana provincial como de la población de sus departamentos Capital, aunque la provincia del Chaco, tiene aún un porcentaje de población rural $(25,8 \%)$ más elevado que el de la provincia de Corrientes $(19,7 \%)$.

Gráfico 4. Incremento porcentual de población urbana provincial y Departamento Capital. 2000/91. Elab. propia en base al INDEC. Serie Análisis Demográfico No 7. 


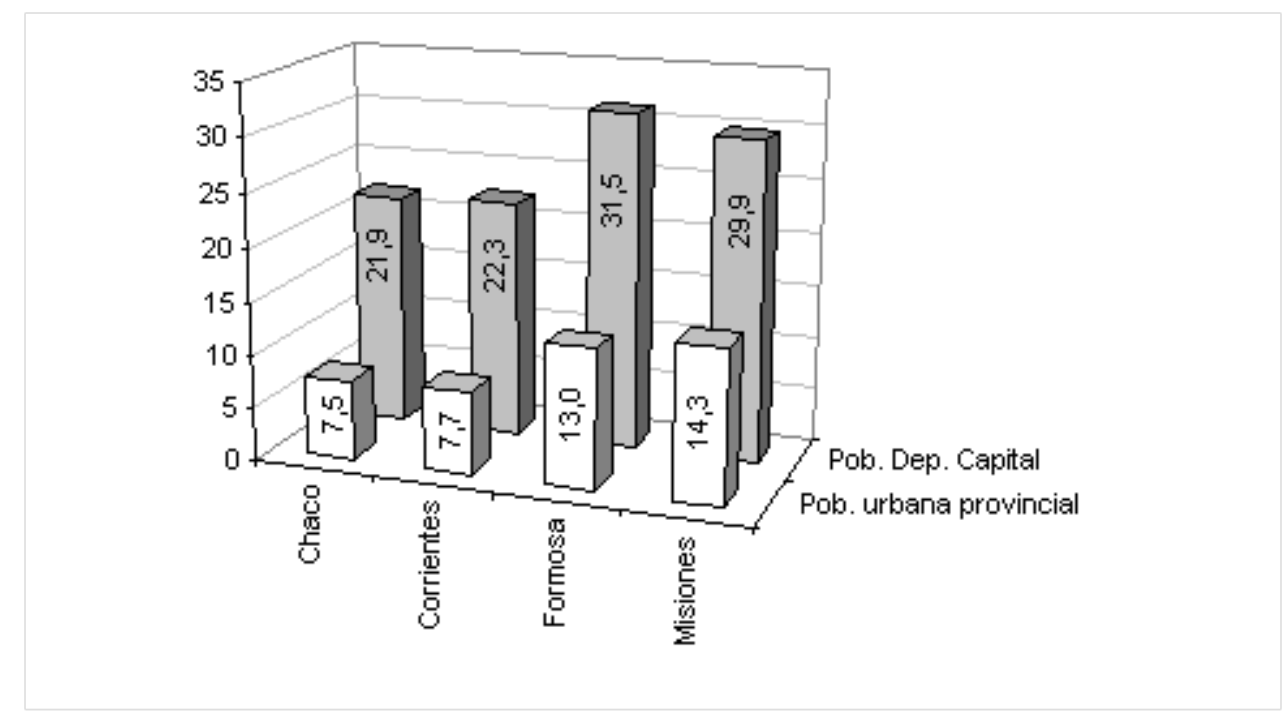

\section{CRECIMIENTO POBLACIONAL, ECONOMÍA URBANA Y POBREZA}

Partiendo de los indicadores ya analizados en el punto anterior, se puede afirmar que el mayor crecimiento porcentual de población de las ciudades capitales provinciales, en relación a las de ciudades de mayor tamaño del país y de sus áreas de influencia, se debe principalmente a las migraciones rurales y también desde los poblados de menor tamaño que se encuentran dentro de los respectivos territorios provinciales y áreas de influencias con las particularidades antes analizadas para cada una de ellas. Existe una combinación de causas muy diferentes que influyen sobre estos procesos de migración que se encuentran asociados a las reformas estructurales antes mencionadas y que presentan múltiples dimensiones, entre las que se pueden citar como importantes, por ejemplo, la reestructuración territorial de la producción agrícola regional, dada por el incremento del tamaño de algunos tipos de unidades productivas expulsoras de población, como los casos de las forestales en Misiones y las algodoneras en el chaco (Ardiaca, 1998), y también la prolongada crisis que afecta a la agricultura minifundista de la región, a partir del proceso de concentración económica dada en la producción agrícola industrial, en concordancia con lo ocurrido en la economía argentina en las últimas décadas.[5] A las que se suman causas tales como la localización territorial de las obras públicas que realizan los Estados nacionales y provinciales, tanto en obras de infraestructura y vivienda, como en políticas sociales y empleos, en el que las ciudades capitales de provincias resultan siempre favorecidas con respecto a los centros de menor tamaño, potenciando aún más la atracción de población a estas ciudades, en la medida que ellas representan fuente de empleo y condiciones de reproducción social más favorable que las del resto de las provincias que la contienen. Aunque no se dispone de abundante información al respecto, a modo de ejemplo se puede citar la cantidad de vivienda pública realizada por el Instituto Provincial de la Vivienda en Misiones (actualmente IPRODHA), que en la ciudad de Posadas desde el año 1972 hasta el 2001 asciende a casi el 40\% del total de viviendas que este organismo construyó en toda la provincia (14.117 de 37.478 unidades), mientras que según el censo de población del 2001, la cantidad de población del Departamento Capital representa el 29,6\% del total provincial, pero además, a estas viviendas deben aún sumarse las que fueron financiadas por el municipio y otros programas especiales. La Entidad Binacional Yaciretá, por ejemplo, financió en la ciudad de Posadas, más de 10.000 unidades de vivienda para población relocalizada por la construcción de la represa de igual nombre. Aunque no se dispone de más información al respecto, se puede afirmar que similar situación ocurre en las otras provincias y en otros rubros del gasto público. Es indudable que decisiones de este tipo no guardan relación con la localización territorial de la población y responden probablemente a alguna lógica que aún resta por dilucidar y que influyen de manera preponderante sobre los procesos migratorios en marcha.

El hecho de que la emigración que hace crecer a estas ciudades se debe más a este tipo de decisiones y a la incontinencia de sus áreas de influencia, que a una demanda efectiva de sus actividades económicas, determina que la población que diariamente llega a vivir a las ciudades de 
Posadas, corrientes, Resistencia y Formosa, más que incorporarse a la estructura formal de la economía de estas ciudades, pasa a engrosar su sector informal, incrementando, a su vez, el producido durante la década pasada por el proceso de centralización y concentración de la economía argentina, que trajo aparejado, como ya se ha dicho, un fuerte incremento de los índices de pobreza, desempleo y demás indicadores sociales y que han llevado a consolidar a la región NEA como la peor de todas las de la Argentina (Siempro, Ob. Cit.).

El motor de la economía de las ciudades intermedias de la región está representado principalmente por las actividades comerciales y de servicios privados que asisten a sus áreas de influencia y por la concentración de la mayor parte de las actividades administrativas y de servicios públicos de dichas áreas. En los inicios de la década del noventa, el proceso de privatización de las empresas del estado y la desregulación y apertura de las actividades económicas, sumados a los efectos de la estabilización de la economía y la expansión del crédito de los inicios del plan de convertibilidad, dinamizó y modernizó algunas actividades comerciales y de servicios vinculadas a los sectores financieros, energéticos, de comunicación y de la construcción, tal como se puede deducir de la evolución de los diferentes sectores del Producto Bruto Geográfico de cada provincia durante ese periodo, sin embargo, dado el estancamiento y la prolongada crisis de la actividad primaria, principal motor de la economía regional, después de la inyección de capital vinculado al proceso de reforma estructural, el motor de la economía de estas ciudades intermedias a pasado a depender, en gran medida, de la transferencia de recursos que las políticas públicas han realizado, tanto en forma de empleos estables y transitorios, como en inversiones para obras de infraestructura y en políticas sociales. En promedio entre las distintas provincias de la región, alrededor de un treinta por ciento de los ocupados trabaja en la administración pública en contraposición al dieciséis por ciento de nivel nacional, de los cuales, la mayor parte de ellos, vive en las capitales provinciales, siendo la provincia de Misiones la que menor proporción representa de todas ellas y la de Formosa la mayor de ellas.

\begin{tabular}{lllllll}
\hline $\begin{array}{l}\text { EMPLEO } \\
\text { Mayo 2000 }\end{array}$ & $\begin{array}{l}\text { Tasa de } \\
\text { actividad } \\
\text { total }\end{array}$ & $\begin{array}{l}\text { Tasa de } \\
\text { empleo } \\
\text { total }\end{array}$ & $\begin{array}{l}\text { Tasa de } \\
\text { desempleo } \\
\text { total }\end{array}$ & $\begin{array}{l}\text { Tasa de } \\
\text { subocup. } \\
\text { total }\end{array}$ & $\begin{array}{l}\text { Ocupados } \\
\text { sector } \\
\text { informal }\end{array}$ & $\begin{array}{l}\text { Ocupados } \\
\text { sector } \\
\text { público }\end{array}$ \\
\hline Total de aglom. urbanos & 42,30 & 35.80 & 15,40 & 14,50 & 45,40 & 16,00 \\
\hline NEA & 33,70 & 30.20 & 10,50 & 12,00 & 50,10 & 28,70 \\
\hline G. Resistencia & 33,60 & 30.10 & 10,40 & 13,60 & 51,50 & 26,70 \\
\hline Corrientes & 35,50 & 31.00 & 12,70 & 11,80 & 45,10 & 32,10 \\
\hline Formosa & 30,50 & 27.40 & 10,30 & 4,30 & 50,90 & 35,30 \\
\hline Posadas & 34,10 & 31.40 & 7,70 & 15,20 & 53,80 & 23,10 \\
\hline
\end{tabular}

Elaboración propia. Fuente: SIEMPRO, en base a datos de la Encuesta Permanente de Hogares -INDEC, mayo 2000.

El fuerte protagonismo que ha adquirido en la economía de estas ciudades el gasto público, en el marco de una baja dinámica del mercado de trabajo y de la actividad económica en general, tal como lo demuestran las bajas tasas de actividad y empleo, con relación a las del resto del país, sumado al alto porcentaje de empleados en el sector informal, que superan a la mitad de los ocupados, más los índices de desempleo y subocupación, (Siempro, Ob. Cit.), ha incrementado la dependencia de los habitantes de éstas ciudades del sector publico en general y el poder político en particular, que sumada a prácticas políticas clientelares, que han vuelto a emerger con mucha fuerza, durante la década del noventa, tanto en el país como en la región, limitan cada vez más el desarrollo de una sociedad civil con capacidad de control democrático sobre el poder político. Este tipo de relaciones entre el poder político y los sectores sociales más necesitados, en el marco de los programas sociales de carácter focalizados, implementados en la Argentina durante la década del ' 90 , en el marco de una cada vez mayor escasez de recursos públicos e incremento de las necesidades sociales, ha incentivado la fragmentación social y la emergencia de innumerables movimientos sociales que realizan permanentes manifestaciones públicas y que demandan atención pública a sus necesidades (Barreto, Benítez, Attías, 2002).

\section{RENOVACIÓN URBANA Y EXPANSIÓN TERRITORIAL}

\section{LA IMAGE N DE LAS CIUDADES}


La inversión del capital privado, vinculado al proceso de reforma estructural y privatización de los servicios públicos, durante la primera mitad de la década del 90, más la inversión pública en obras de infraestructura vial y urbana, realizada a través de financiación de organismos internacionales de créditos (Barreto, Zavala, 2002), impactó en la remodelación de determinados sectores de estas ciudades, merced a la revitalización de áreas deterioradas o en expansión y la renovación y surgimiento de una serie de nuevas actividades financieras, comerciales y de servicio y contribuyó a cambiar la imagen urbana en determinadas áreas de la ciudad. En la ciudad de Posadas, la expansión del sector financiero ha renovado la imagen del centro de la ciudad e importantes inversiones en obras públicas de carácter vial, espacios públicos y servicios han valorizado importantes sectores urbanos antiguamente ocupados por población de bajos recursos, tales como la avenida costanera y una serie de otras avenidas, la nueva terminal de ómnibus, y varias plazas y otros espacio públicos, también lo ha hecho el sector comercial a partir de la expansión de las grandes superficies cubiertas (supermercados e hipermercados). En las ciudades de Resistencia Corrientes y Formosa, también se construyeron edificios de servicios similares y se realizaron importantes obras de carácter vial, en Resistencia también se construyó una nueva terminal de ómnibus, se remodeló la plaza central y otros espacios públicos, aunque, en esta última ciudad, la gran obra pública, fue la de las defensas contra las inundaciones, que aunque no impactó sobre la imagen de la ciudad, tuvo efectos importantes en la expansión urbana, como se verá más adelante. También tuvo cierta incidencia en la imagen de éstas ciudades, durante este periodo, la promoción inmobiliaria ligada al incremento de los créditos hipotecarios para vivienda, como consecuencia de la reforma del mercado de capitales. Estas inversiones permitieron el incipiente desarrollo de nuevas áreas urbanas residenciales destinadas a sectores sociales medios y altos, tales como las márgenes de la avenida Urquiza, y áreas como "la cumbre" en la ciudad de Posadas, o las márgenes de la avenida Sarmiento en cercanías al Río Negro en la ciudad de Resistencia y algunos enclaves al norte de la ciudad de Corrientes, que se ha caracterizado por promover una arquitectura con fuerte connotaciones simbólicas de clase.[6]

En otro trabajo se ha criticado las prioridades en las obras públicas establecidas por las Unidades Ejecutoras Provinciales que administraron los créditos provenientes de los organismos financieros internacionales, tales como el Banco Mundial, el Banco Interamericano de Desarrollo y otras entidades de promoción del desarrollo en regiones periféricas del mundo, seriamente cuestionadas por sus resultados, dado que operaron como centros cerrados de decisión y ejecución de políticas verticalistas de inversión, basadas en esquemas de funcionamiento pre-fijados por estos organismos, y lejos de llevar a cabo programas de inversión consensuados por la ciudadanía y sus representantes directos (Barreto / Zavala, 2002a).

Sin embargo, a pesar del impacto que tuvieron estas obras sobre la imagen urbana de estas ciudades, todas estas inversiones de capital tuvieron poca importancia en la expansión territorial de las ciudades intermedias de la región. Los principales protagonistas del crecimiento urbano han sido las obras de vivienda públicas y el silencioso trabajo de los sectores populares, entre los que se destaca el trabajo autogestionario de los pobres que han estado viniendo a vivir a estas ciudades. Estos últimos han sido uno de los principales protagonistas de la expansión urbana de las ciudades intermedias de la región.

\section{LA PRODUCCIÓN DEL HÁBITAT POPULAR}

Se pueden diferenciar tres formas de producción del hábitat popular que han contribuido a la expansión urbana de las ciudades intermedias de la región en las últimas décadas: los loteos económicos, las "villas miserias" y los asentamientos o ocupaciones como producto de tomas masivas y organizadas de tierras desocupadas por parte movimientos sociales de diferentes origen. Los loteos económicos han sido el resultado de subdivisiones de parcelas periurbanas realizadas por empresas inmobiliarias locales con la finalidad de ser vendidas a largo plazo a los sectores populares de pequeña capacidad de ahorro y estabilidad laboral para hacer frente al pago de pequeñas cuotas e iniciar la construcción de una vivienda económica pequeña y evolutiva. Generalmente se tratan de tierras desprovistas de gran parte de la infraestructura básica de servicios, contando generalmente sólo con luz eléctrica y trasporte público de pasajero. Esta modalidad de producción tuvo mucha importancia en las ciudades de la región hasta la década del 80 y durante los noventa estuvo en baja casi hasta desaparecer, en concordancia con el proceso de precarización laboral de los sectores populares y la disminución de su capacidad de ahorro, aunque todavía es posible encontrar en los diarios de las ciudades de Posadas y Corrientes promociones inmobiliarias de este tipo, en cambio, en 
la ciudad de Resistencia a disminuido casi hasta desaparecer debido a la exigencia municipal que obliga a las inmobiliarias la provisión de toda la infraestructura básica para realizar la subdivisión, lo cual, según los agentes inmobiliarios de esa ciudad, encarece el costo de las parcelas y limita fuertemente la demanda, (Diario Norte, edición del 15-03-98).

Por su parte, las "villas miserias" y los asentamientos o ocupaciones, si bien son formas "ilegales" de acceso al suelo, ha sido el recurso del que dispusieron históricamente los más excluidos de la sociedad para vivir en la ciudad, la villa ha sido la forma más tradicional del hábitat popular urbano de la región y ha sido el resultado de lentas y no planificadas ocupaciones de tierras urbanas y suburbanas interticiales de muy baja calidad (anegadizas, pantanosas, etcétera.), Esta forma de ocupación, a pesar de ser "ilegal" y cuestionar un valor social fundamental como el derecho de propiedad del suelo, generalmente no ha generado resistencia por parte de las autoridades o propietarios de suelo porque fueron realizadas sobre tierras cedidas a tal fin o abandonadas y de poco interés como han sido las márgenes bajas de arroyos urbanos, ríos y las lagunas existentes en estas ciudades, sobre las cuales, ha existido hasta hace sólo una década atrás escasa presión por parte de las empresas inmobiliarias y el mercado de suelo en general, aunque, en las últimos tiempos, a causa del avance de la infraestructura urbana, muchas de ellas están siendo forzadas por el mercado inmobiliario o por programas públicos de consolidación y relocalización a regular su situación dominial o ser trasladas hacia áreas más periféricas de la ciudad, tal como ha ocurrido y está ocurriendo en los márgenes costeros noreste de la ciudades de Posadas, Corrientes y Resistencia. Las villas fueron las formas predominantes de ocupación del suelo por parte de emigrantes rurales pobres que han venido a vivir a estas ciudades hasta la década del 80 aproximadamente y se ha caracterizado por configurar una hábitat de crecimiento gradual y no planificado, fuertemente influenciado por las prácticas rurales de vida y de construcción del hábitat.

En cambio, los asentamientos o ocupaciones son el resultado de tomas más masivas y organizadas realizada por nuevos grupos o movimientos sociales organizados previamente con este fin (ver los trabajos de Benítez y Pratesi en esta publicación). Esta forma de ocupación generalmente se realiza en base a planificaciones previas de las tierras a ocupar, en las que las subdivisiones del loteo suelen tener en cuenta el tejido urbano de la ciudad y las construcciones se realizan con un criterio de vivienda evolutiva. Las tierras ocupadas de esta manera generalmente son de mayor interés, por este motivo el cuestionamiento al derecho de propiedad suele ser más explícito, y en algunos casos, como el de la "rubita" en la ciudad de Resistencia, terminan siendo conflictivas, Tal como señalaron algunos autores (Benítez, 2000; Sbrocco, 2000, etcétera) esta forma de ocupación es realizada por pobladores que no tienen otro medio de acceder al suelo, pero que a la vez quieren diferenciarse de los habitantes de las villas de emergencia, en la medida que expresan su interés en "legalizar" su situación y construir con el tiempo un barrio para integrarse a la ciudad, claramente se trata una estrategia llevada a cabo por los sectores sociales excluidos del modelo actual que se encuentran en franca expansión.

Este forma de producción del hábitat se ha practicado de manera corriente en la ciudad de Resistencia en los últimos años, donde los "ocupantes" han desarrollados formas de articulación con el poder político y organizaciones civiles para su desarrollo. Ella ha estado en franco crecimiento en esta ciudad, hasta convertirse en la actualidad en la más importante de todas, en parte, porque tal como ya se ha señalado, el Código de Planeamiento Urbano exige a los propietarios de tierras urbanizables de la ciudad de Resistencia la inversión en obras de infraestructura básica y la donación de un porcentaje de esas tierras para la red vial de la ciudad como condición para su oferta en el mercado de suelo. Lo cual, de acuerdo a los empresarios inmobiliarios locales, encarece en demasía el precio de los terrenos en las áreas urbanas populares y les impide realizar los llamados "loteos económicos". Pero, en parte también, porque el gobierno provincial, a creado un instrumento jurídico que mediante compras compulsivas, expropia a los propietarios las tierras ocupadas para otorgárselas a sus ocupantes a un muy bajo precio. De esta manera, las ocupaciones masivas de tierras urbanizables en áreas de bajo valor económico y las expropiaciones de las mismas a sus propietarios, se han generalizado como política de tierra y se ha vuelto el principal mecanismo de acceso al suelo por parte de los pobres de la ciudad. Situación que en el marco de la acción política clientelar a llevado a que las ocupaciones en muchos casos se negocien políticamente y sean avaladas previamente y hasta promovidas por los dirigentes políticos y propietarios de suelo, que han encontrado en este mecanismo, la manera de vender sus propiedades sin realizar las inversiones económicas previas que exige el Código Urbano Municipal. 
Este mecanismo de asignación de tierra, sin embargo, en el contexto del acelerado incremento de la población pobre a causa de la migración rural, ha desbordado ampliamente la acción política del gobierno y ha hecho explosión en los dos últimos años en la ciudad. En junio del 2001 existían alrededor de 15 ocupaciones masivas ocurridas recientemente que estaban en conflicto y exigían al gobierno la expropiación de las tierras ocupadas.

\section{LA PRODUCCIÓN DEL HÁBITAT POR PARTE DEL ESTADO}

El otro gran hacedor de las ciudades intermedias de la región ha sido el Estado a través de las obras de infraestructura, principalmente a través de la construcción de viviendas en forma de nuevas urbanizaciones, es decir, de conjuntos habitacionales ubicados en las periferias urbanas con la finalidad adicional de extender el tejido de la ciudad. Estas urbanizaciones fueron modificándose en su concepción desde sus inicios, al principio, en la década del 60 , se construyeron en forma de viviendas individuales respetando el trazado tradicional de la ciudad, desde fines de la década del 70, con la creación del Fondo Nacional de la Vivienda (FONAVI), se intensificó la producción en forma de edificios colectivos de densidad poblacional media, ubicados sobre trazados urbanos diferentes al damero de la ciudad y, en los últimos tiempos, nuevamente han vuelto a la forma urbana tradicional de la región: viviendas individuales de baja densidad poblacional sobre manzanas estándares, aunque sobre una base de mayor diversidad de programas orientados a diferentes tipos de población objeto.

Estos conjuntos habitacionales durante estos tres periodos no han modificado el tipo de urbanidad que promueven y por la cual fueron criticados en otras latitudes, continúan siendo concebidos como simples unidad de habitación bajo los parámetros del funcionalismo moderno, sin promover una urbanidad más diversificada que contribuyan a crear una mayor integración social en el espacio público. Desde una concepción urbana socialmente más integrada ( Jacob, 1973; Ariès, 1981; Berman, 1982), se puede afirmar que las periferias de las ciudades intermedias de la región, a raíz de la concepción del espacio público prevalecientes en estas formas de producción del hábitat residencial, se han vuelto socialmente pobres, compuestas solamente por barrios de baja calidad ambiental con muy pocos lugares para la sociabilidad pública que permitan una forma de vida urbana más integrada entre sus diferentes sectores sociales. En estas áreas la vida urbana se está restringiendo cada vez más al ámbito doméstico y el espacio público se está volviendo sólo para circular o para quienes deambulan para vivir. Las necesidades económicas, la inseguridad y el error de los planificadores esta matando la vida social de estas ciudades. El auto encierro se está imponiendo como norma de vida, Sonia Álvarez, espejando a Marc Auge (1993) señaló "La modernidad a medias características de estas ciudades -ella se refiere a la ciudad de Salta- no esta exenta de soledad. Esta no es una soledad desterritorializada como la de sobre-modernidad, sino fuertemente localizada en una ciudad / no ciudad. Es un "no lugar" sui generis de la urbanización periférica.

Es así como se han extendido considerablemente en estas ciudades en las últimas décadas, las áreas urbanas de baja calidad ambiental y servicios deficientes, grandes manchas urbanas que se caracterizan por calles en mal estado, sin veredas, con malos servicios de transporte, recolección de residuos, luz y agua potable, hasta transformarse su paisaje al grado de haber invertido en algunos casos (como Resistencia) la vieja imagen que de ellas se tenían, Al respecto Beatriz Cuenya ha señalado que "ya no se tratan de ciudades con estándares de vida más o menos aceptable con algunos bolsones de pobreza, sino de ciudades pobres con algunos bolsones de riqueza" (Cuenya, 1997).

\section{PLANIFICACIÓN Y SEGMENTACIÓN DEL ESPACIO URBANO}

Como ya se ha venido señalando, una característica importante de la expansión urbana de las ciudades intermedias del nordeste argentino en las últimas décadas tiene que ver con la segmentación social del espacio urbano, al respecto, debe señalarse que sobre la misma ha jugado un papel destacado la obra pública, nos sólo la política de vivienda, tal como ya se ha empezado a describir anteriormente, sino también algunas grandes obras de infraestructura, como el caso de las defensas definitivas contra las inundaciones en la ciudad de Resistencia y las obras complementarias de la Represa de Yaciretá en la ciudad de Posadas (a las que le seguirá la Costanera Norte en la Ciudad de Corrientes), las cuales junto a otras obras de carácter vial implicaron el desplazamiento voluntario e involuntario de población y la reestructuración física del espacio urbano, lo que trajo aparejado la 
configuración de nuevas áreas urbanas de homogeneidad social interna y heterogeneidad social externa (segregación urbana).[7]

Entre el 25 y $35 \%$ de las viviendas que actualmente existen en estas ciudades han sido financiadas por el Estado a través de diversos programas, la mayor parte de ellos administrados por los Institutos Provinciales de Vivienda, los cuales, además de haber provisto de vivienda a un vasto sector de población de recursos medios y bajos, tuvieron la finalidad adicional de extender el tejido urbano de estas ciudades merced a la construcción de viviendas en formas de conjuntos habitacionales con infraestructura básica,[8] y salvo algunas excepciones, estas obras han extendido una zona determinada de las ciudades, en Resistencia fue el borde suroeste en forma de franja irregular entre las avenidas Castelli - Alvear y Soberanía Nacional (Plano 1); en Posadas, también el borde suroeste, acompañando las márgenes de los arroyos Mártires al Oeste y Zaimán al sur (Plano 2) y en Corrientes fue el sur y el este de la ciudad (Plano 3). Y lo han hecho de manera tal que han ido generando espacios intersticiales en los cuales se ha asentado población de sectores bajos y medios bajos por cuenta propia en algunas de las modalidades descriptas anteriormente.

\section{Plano 1}

POSADAS. Viviendas financiadas por el Estado

Elaboración propia en base a información municipal.

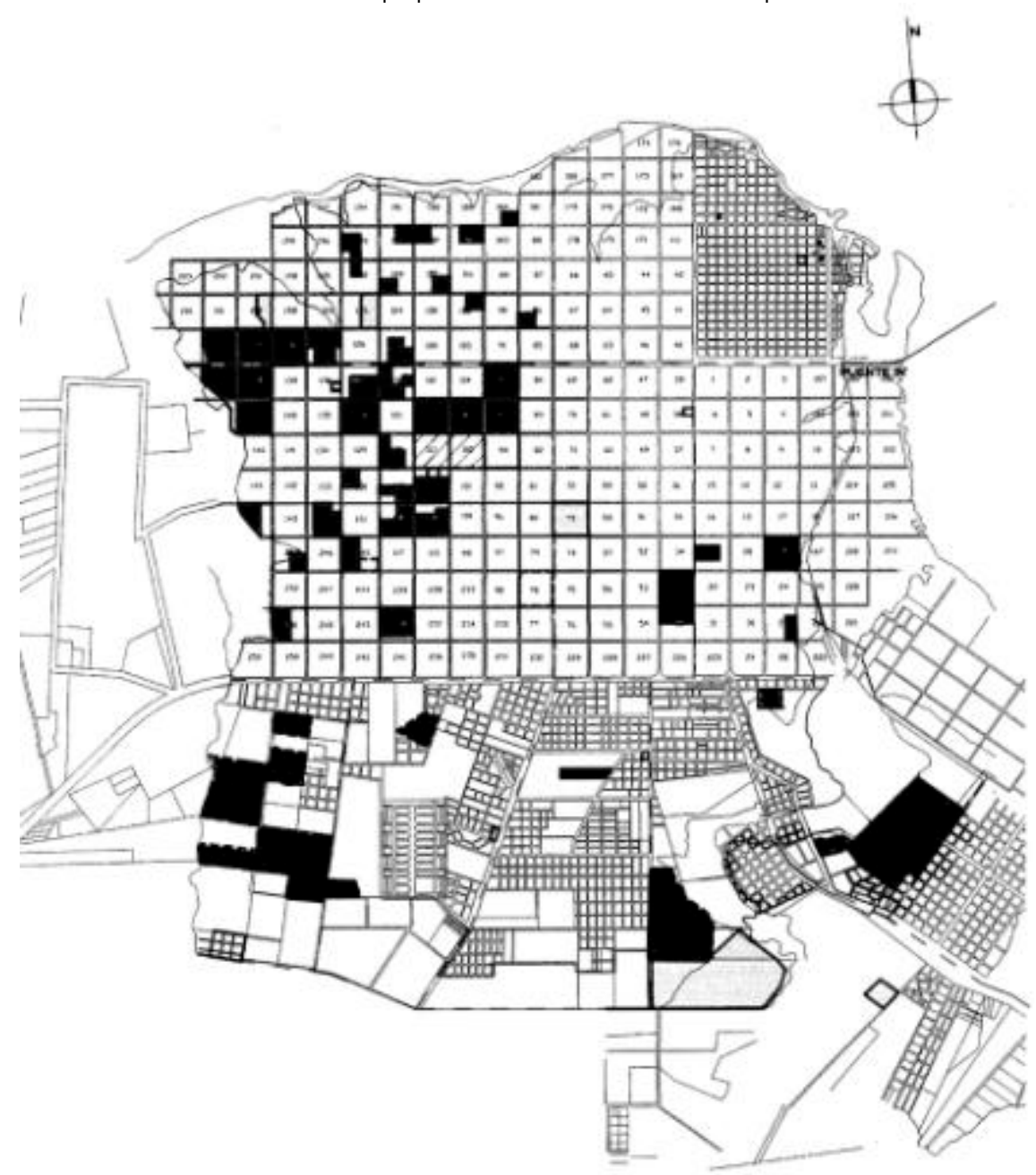

Plano 2

CORRIENTES. Viviendas financiadas por el Estado

Elaboración de Lorena Sánchez en base a información municipal. 


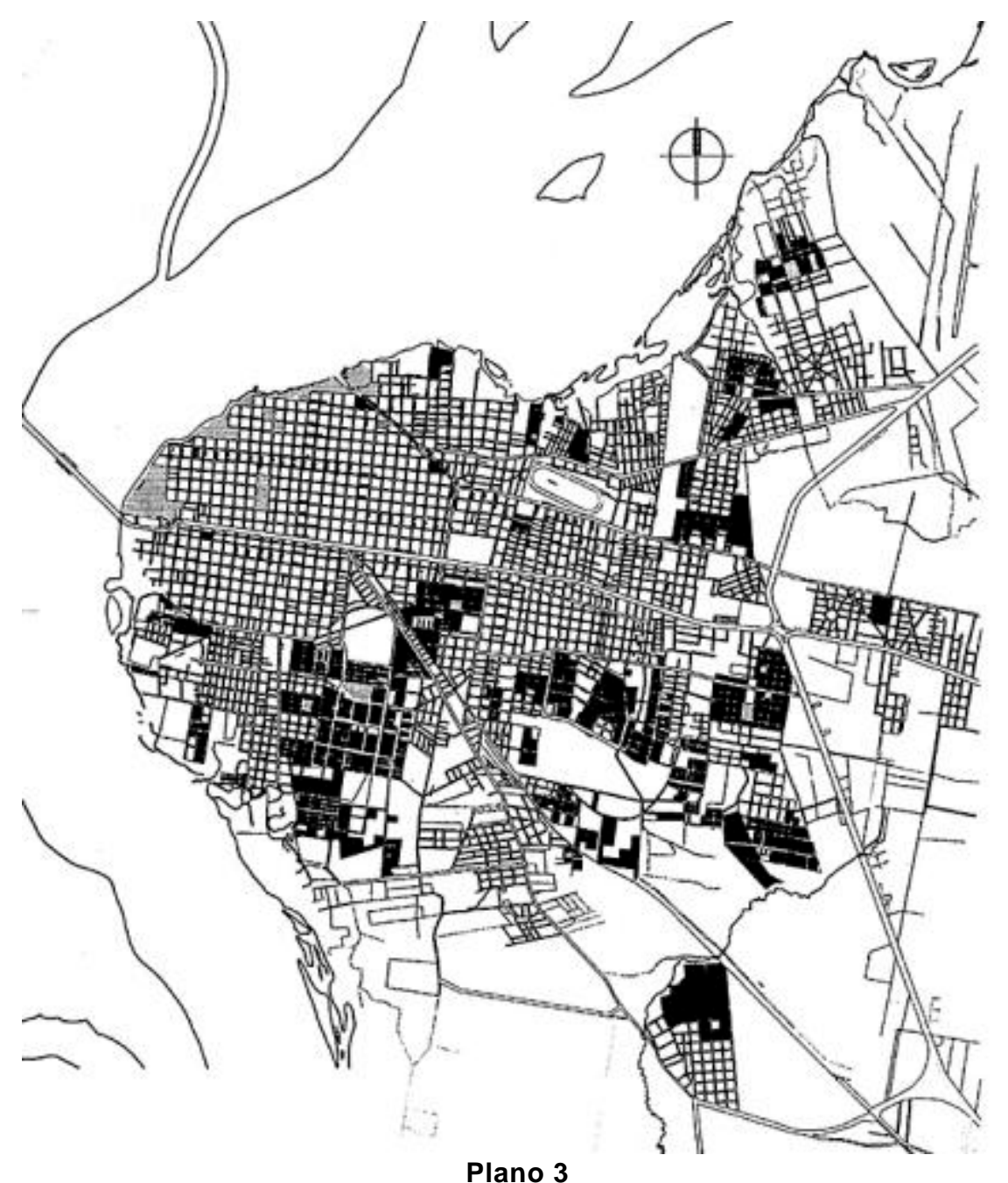

RESISTENCIA. Viviendas financiadas por el Estado Elaboración propia en base a información municipal. 


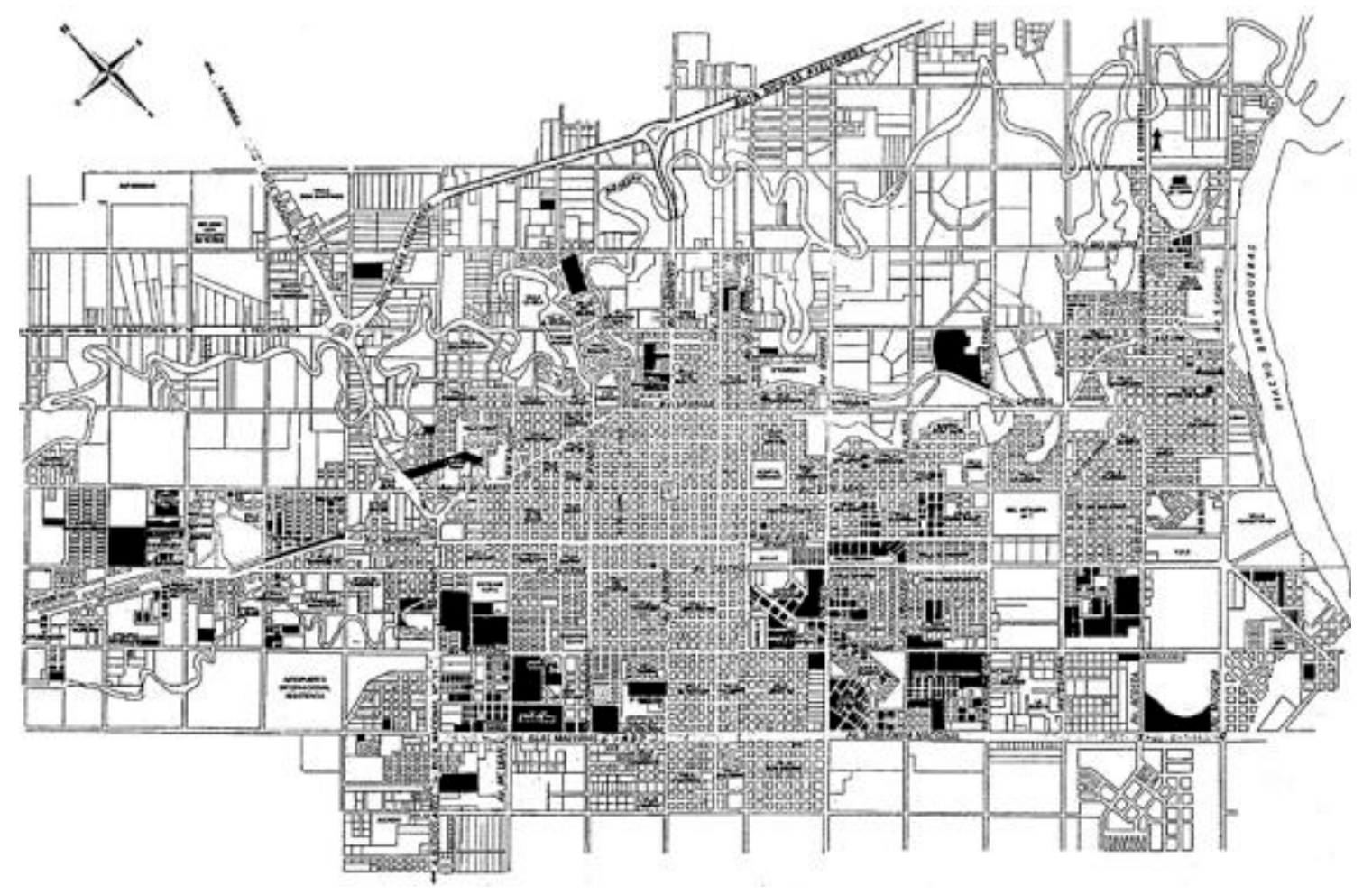

Por su parte en la ciudad de Resistencia y de Posadas se están llevando ha cabo dos grandes programas de obras de infraestructura financiado por organismos internacionales de créditos, el Plan de Defensas definitivas contra las inundaciones y el programa de obras complementarias de la represa de Yaciretá respectivamente, los cuales han causado e inducido de manera considerable el traslado voluntario e involuntario de población de bajos recursos desde áreas recientemente valorizadas, hacia las áreas promovidas por las políticas habitacionales ante descriptas. En la ciudad de Posadas, además de la construcción del puente Posadas-Encarnación, el gobierno está llevando a cabo una serie de obras viales que ha producido el mismo efecto de segregación, la avenida costanera es el más claro ejemplo de todas ellas (Barreto, Zavala, 2002b).

Estas ciudades al igual que Corrientes y Formosa son costeras, Posadas está ubicada al margen del río Paraná y Resistencia al margen del río Negro en su desembocadura con el anterior, sin embargo, sus costas, a pesar de ser de alta calidad ambiental, debido a que eran inundables periódicamente, fueron ocupadas por población de bajo recurso, salvo en los lugares más altos y próximos a los centros de las ciudades, como los barrios Aguacates, Villa Sarita, Baradero y Cerro Pelón en Posadas y los barrios del Parque Ávalos, Golf Club y La Liguria en Resistencia, que fueron ocupados por sectores medios altos. Pero estas grandes obras de infraestructura han modificado esta situación, en la ciudad de Resistencia el Plan de Defensas ha recuperado para la ciudad, la zona costera del río Negro y a través de un largo y complejo proceso de articulación entre políticas públicas e intereses privados en torno a las inundaciones recurrentes (Barreto, 1993, 1998), en las últimas dos décadas, han inducido el paulatino traslado de población de bajos recursos desde estas áreas hacia otros sectores de la ciudad y ha promovido en ellas inversiones privadas orientadas al desarrollo de áreas residenciales para sectores medios y medios altos, y, en la ciudad de Posadas, ha ocurrido algo similar, con la diferencia que las políticas de traslado compulsivo han sido más masivas y directas debido a la magnitud que ha tenido sobre ella el impacto de la represa de Yaciretá, y se contempló la provisión de viviendas para la población erradicada, sin embargo este proceso no ha estado exento de conflictos, los cuales, aún persisten. (Diario Primera Edición, edición del 20-08-00)

Una de las viejas características de estas ciudades intermedias era que disponían en torno al casco céntrico primario, de un espacio urbano residencial sumamente heterogéneo en el que los diferentes niveles socio-económicos estaban entremezclados, esto se debía principalmente al desarrollo de asentamientos de población pobre en las tierras urbanas intersticiales de bajo valor. Esta característica eran marcadas en las ciudades de Posadas y Resistencia debido a que existían muchas 
tierras de este tipo en las márgenes de los arroyos (en Posadas) y lagunas (en Resistencia). En forma paralela a las obras de infraestructura que tornaron habitables estas tierras, en las dos últimas décadas, estos procesos de reubicación de población han contribuido a la segmentación social del espacio urbano ayudando a definir áreas socio económicas más homogéneas. Así, en el suroeste de Resistencia y Posadas se han configurado grandes áreas urbanas de sectores de población bajos y medios bajos y en el noroeste se han incrementado los enclaves residenciales de población media y media alta.

Sin embargo, la ciudad de Posadas presenta algunas diferencias cualitativas al respecto, debido a que en su margen suroeste se han desarrollado actividades que movilizan población de otros niveles socio-económicos hacia las inmediaciones a los accesos a la ciudad, tales como el campus universitario, clubes deportivos, aeropuerto, terminal de ómnibus, parques, cementerios privados, etcétera, en cambio, en Resistencia, solamente la terminal de ómnibus y el aeropuerto lo hacen, quedando aisladas grandes áreas urbanas residenciales de baja calidad ambiental, en esta ciudad hasta la ubicación de los cementerios públicos y privados contribuyen a la diferenciación social. En el sentido inverso también existe esta diferencia cualitativa entre Posadas y Resistencia, la avenida costanera recientemente construida es un espacio público ubicado dentro de una de las áreas residenciales más valorizadas de la ciudad a la que concurren a pasear diferentes niveles socio económicos, en cambio en la ciudad de Resistencia no existe esta posibilidad. En relación a esta cuestión no se dispone de suficiente información respecto de la ciudades de Corrientes y Formosa.

\section{CONCLUSIONES}

La finalidad del presente trabajo ha sido analizar las principales características del crecimiento urbano de las ciudades intermedias capitales provinciales de la región nordeste de la Argentina, durante la década del noventa, en el marco de las transformaciones estructurales ocurridas durante ese periodo, expresadas en la reforma del Estado, la apertura económica, la concentración y centralización del capital y la integración de los principales mercados del Sur (MERCOSUR). Al respecto, se han analizado algunas características sobresalientes de los procesos de urbanización de cada de las diferentes provincias de la región, la distribución de su población en el territorio y el destacado rol protagónico que la ciudades capitales de provincia, están desempeñando en la actual reestructuración territorial de la población de la región.

Los aspectos más importantes del crecimiento urbano de estas ciudades durante este periodo estuvieron asociados, al impacto producido a principios de la década pasada por el proceso de privatización de las empresas del estado, la desregulación y apertura de las actividades económicas y los efectos iniciales de la estabilización de la economía y la expansión del crédito, que dinamizó y modernizó algunas actividades comerciales y de servicios vinculadas a los sectores financieros, energéticos, de comunicación y de la construcción, como así también, al gasto público que durante todo el periodo realizó el Estado en obras de infraestructura, equipamiento público, vivienda y políticas sociales, financiadas y decididas por créditos de organismos financieros internacionales y que incentivó el proceso de urbanización de la población. Pero, sin duda que uno de los aspectos más sobresaliente del crecimiento urbano a sido la expansión urbana promovida por el trabajo autogestionario de la población proveniente de áreas rurales y centros urbanos de menor tamaño, afectados por la exclusión social que produjo el proceso de concentración económica ocurrido durante el periodo analizado.

El resultado sobre el espacio urbano de estos procesos trajo aparejado, por una parte, la renovación de la imagen urbana del centro de estas ciudades y de algunas áreas revalorizadas, como producto del gasto público en obras de infraestructura y la inversión privada en el sector comercial de servicios e inmobiliario, mientras que, por otra parte, la expansión de grandes áreas residenciales de baja calidad ambiental y servicios deficientes como producto de la acción autogestionaria de los sectores populares y la política habitacional pública, que han contribuido a definir un espacio urbano de contrastes y fragmentación social.

Sobre este proceso tuvo además una incidencia importante la segregación urbana producida por la implantación de grandes obras públicas de infraestructura que contribuyeron a redefinir áreas socialmente más homogéneas hacia su interior y dispares entre ellas, en términos jerárquicos, como 
así también, la baja calidad del espacio público de estas áreas promovido por las políticas públicas, que no han contribuido a la integración social de la población.

Cabe aclarar que estas características distintivas del crecimiento urbano de las ciudades intermedias capitales provinciales de la región nordeste de la Argentina durante la década pasada, señaladas en esta conclusión presentan matices y diferencias entre las respectivas ciudades analizadas, y que en algunos aspectos alcanzan a ser importantes, tal como se ha señalado a lo largo del presente trabajo.

\section{BIBLIOGRAFÍA}

ÁLVAREZ, SONIA

2000. "Los pioneros modernos, hacedores invisibles de una ciudad a medias" En: RABEY, Mario y JEREZ, Omar (eds.) Procesos de urbanización en la argentina: La mirada antropológica. Universidad Nacional de Jujuy, Jujuy. Pp. 59-107.

ARDIACA, D.

1998. "La Argentina que crece y la que espera". En Revista Mercado. Buenos Aires, Edición del mes de Abril.

ARIÈS, PHILIPPE

1981. "A familia e a Cidade". En VELHO, G. FIGUEIRA, S. (coord.). Familia, psicología e sociedade, Editora Campus, Río de Janeiro.Pp. 13-23.

AUGE, MARC

1993. Los no lugares. Espacios del anonimato, Barcelona, Gedisa.

BARRETO, MIGUEL.

1993. "Inundaciones en el Gran Resistencia durante 1982-83. Comportamiento del Sistema Urbano y la renta del suelo durante la crisis". Cuaderno $N^{0}$ 1. Cátedra de Sociología Urbana, Facultad de Arquitectura, Secretaria General de Ciencia y Técnica, Universidad Nacional del Nordeste. Resistencia. pp. 7-47.

1999 "La producción de suelo urbano en el Área Sur de la ciudad de Resistencia durante la década del '80”. Ponencia en el XXII Congreso de la Asociación Latinoamericana de Sociología (ALAS). Universidad de Concepción, Chile.

2000. La imagen de la vivienda. Una antropología de las formas urbanas de la ciudad de Posadas, Ed. Universitaria, Posadas.

BARRETO, MIGUEL; SÁNCHEZ, LORENA

2000. "El crecimiento de las ciudades Intermedias del NE Argentino en el contexto de las transformaciones regionales". Publicación electrónica (CD ROM) del Seminario Internacional El rol de las ciudades intermedias iberoamericanas Organizado por Gobierno de la Provincia del Chaco, UNNE, Municipalidad de Resistencia, FADEA, UIA y UNESCO.

BARRETO, MIGUEL ÁNGEL, ZAVALA, JOSÉ.

2002a. "Articulación Vertical de la inversión urbana en el Nordeste Argentino. Reflexiones sobre la experiencia del Banco Mundial durante la década del '90". Ponencia del Tercer Congreso Internacional de Urbanismo y Medio Ambiente: Los Retos de la Planeación Urbano-Ambiental en el Nuevo Siglo. Toluca, México.

2002b. "La tramapa de la memoria. La arquitectura como emblema de procesos urbanos". Revista Área $N^{\circ} 10, F A U$, UBA, Buenos Aires.

BASUALDO, EDUARDO M.

2000. Concentración y centralización del capital en la Argentina durante la década del noventa. Universidad Nacional de Quilmes, Buenos Aires.

BENÍTEZ, MARÍA A.

2000. "De la "villa" al "barrio". Hipótesis sobre construcción de identidades derivadas de la ocupación de tierras urbanas". Ponencia presentada al CAAS 2000. IV Congreso Argentino de Antropología Social. Mar del Plata.

BERMAN, MARSHALL

1982 Todo lo sólido se desvanece en el aire. La experiencia de la modernidad, Siglo XXI, Buenos Aires.

CASTELL, MANUEL

1974. La cuestión urbana, Siglo XXI, México.

CUENYA, BEATRIZ 
1997. "Cambios en el contexto urbano y socioeconómico y su impacto en las condiciones habitacionales de la población. La situación argentina con referencia a América Latina." Cuadernos del CEUR. Bueno. Aires.

DIARIO PRIMERA EDICIÓN, POSADAS.

DIARIO NORTE, RESISTENCIA.

JACOB, JANE

1973. Muerte y vida de las grandes ciudades. Madrid. Península.

LUNGO, MARIO

1995. "América Latina hacia el final del siglo XXI ¿Se está configurando un nuevo patrón de urbanización?" En: DIAZ ORUETA, F. y MIRA, E. (Eds.) Pensar y vivir la ciudad. Departamento de Ciencias Sociales. Universidad de Alicante.

SBROCCO, MARÍA E.

2000. "Asentamientos: entre la estrategia y la gestión. Salta 1997" En: RABEY, Mario y JEREZ, Omar (eds.) Procesos de urbanización en la argentina: La mirada antropológica. Universidad Nacional de Jujuy, Jujuy. Pp. 109-135.

INDEC

2000. Anuario Estadístico de la República Argentina, INDEC, Buenos Aires.

2001. Anuario Estadístico de la República Argentina, INDEC, Buenos Aires.

2001. Censo Nacional de Población y Vivienda 2001 (Resultados provisorios brindados por las sedes provinciales del INDEC).

Información disponible en www.indec.gov.ar

HABITAT II.

1995. "Los asentamientos humanos en América Latina y El Caribe". Informe de Reunión Regional de América Latina y El Caribe Preparatoria de la Conferencia de las Naciones Unidas sobre los Asentamientos Humanos realizada en Santiago de Chile.

SIEMPRO

2000. SIEMPRO, "Informe de Situación Social No 7. Diagnóstico social de la provincia del Chaco". SIEMPRO, Buenos Aires.

2001. "Informe de Situación Social N 8. Diagnóstico social de la provincia de Formosa". SIEMPRO, Buenos Aires.

2001. "Informe de Situación Social Nº 9. Diagnóstico social de la provincia de Misiones". SIEMPRO, Buenos Aires.

2001. "Informe de Situación Social № 10. Diagnóstico social de la provincia de Corrientes", SIEMPRO, Buenos Aires.

2001. "Informe de Situación Social No 11. Diagnóstico social de la provincia del Chaco". SIEMPRO, Buenos Aires.

[1] Una primer versión de este trabajo fue realizada en colaboración con Lorena C. Sánchez. Ver: Barreto, M.; Sánchez, L., 2000)

[2] La región NEA está compuesta por las Provincias de Chaco, Corrientes, Formosa y Misiones. Limita al norte y al este con las Repúblicas del Paraguay, del Brasil y del Uruguay y al sur y al oeste con las Provincias de Salta, Santiago del Estero, Santa Fe y Entre Ríos, según el Censo 2001, tiene 3.359.495 habitantes y una extensión aproximada de $290.000 \mathrm{~km}$. El perfil productivo de la región está dado por la producción primaria, es una de las regiones menos desarrolladas del país, y se encuentra claramente desfavorecida en los indicadores sociales con respecto a este.

[3] La categoría de Población Rural adoptada es la del INDEC, que define como tal a la que habita en áreas rurales y centros urbanos de menos de 2.000 habitantes.

[4] El concepto de "ciudad intermedia" usualmente se basa en dos indicadores diferentes: uno cuantitativo, referido al número de habitantes que contienen, el cual es variable de acuerdo a distintos autores y de escasa precisión ya que llega a comprender un rango muy amplio que incluye a ciudades de entre cincuenta mil y dos millones de habitantes; 
y el otro indicador es de carácter cualitativo, referido a la función o el rol de intermediación (económica, política, cultural, etc.) que una ciudad desempeña en la organización socio-territorial de un país o región.

[5] Se puede tomar como situación paradigmática, el caso de los productores de yerba mate de la provincia de Misiones quienes desde hace tiempo atraviesan un sistemático proceso de empobrecimiento a raíz de los precios constantemente decreciente de su producto primario (la hoja verde), sin que el precio final del producto industrializado (la yerba mate) se haya modificado sustancialmente a favor de una creciente expansión de la rentabilidad del sector molinero y supermercadista. Esta situación que se repite en la mayoría de las cadenas de producción de los productos agrícolas regionales, señala una profunda transformación de la producción minifundista tradicional, forzada a incrementar sus volúmenes de producción a expensas de la extinción de numerosas unidades de producción pequeñas.

[6] Para la ciudad de Posadas, ver: Barreto, 2000.

[7] Castells (1974: 204) definió a la segregación urbana como "Ia tendencia a la organización del espacio en zonas de fuerte homogeneidad social interna y de fuerte disparidad entre ellas, entendiéndose esta disparidad no sólo en términos de diferencia, sino de jerarquía.

[8] En este aspecto, las políticas fueron dispares, en la ciudad de Posadas, en general, las nuevas urbanizaciones fueron acompañadas de mayor calidad de infraestructura respecto de Resistencia, Formosa y Corrientes, sobre todo en lo que respecta a pavimento, cordón cuneta y vereda, que marcaron diferencias en la calidad de los espacios urbanizados, por su parte el Instituto de Vivienda de Corrientes, ha realizado un mayor esfuerzo tendiente a mejorar arquitectónicamente dichos conjuntos. 